\title{
Perceptions and impact of bipolar disorder in Japan: results of an Internet survey
}

\author{
This article was published in the following Dove Press journal: \\ Neuropsychiatric Disease and Treatment \\ 21 November 2016 \\ Number of times this article has been viewed
}

\author{
Koichiro Watanabe' \\ Eiji Harada ${ }^{2}$ \\ Takeshi Inoue ${ }^{3}$ \\ Yuka Tanji ${ }^{2}$ \\ Toshiaki Kikuchi'
}

'Department of Neuropsychiatry, Kyorin University, School of Medicine, Tokyo, ${ }^{2}$ Medical Science, Medicines Development Unit-Japan, Eli Lilly Japan KK, Hyogo, ${ }^{3}$ Department of Psychiatry, Tokyo Medical University, Tokyo, Japan
Correspondence: Yuka Tanji

Medical Science, Eli Lilly Japan KK, 7-I-5, Isogamidori, Chuo-ku, Kobe 65I-0086,

Hyogo, Japan

Tel +8I 782429197

Fax +81 782429526

Email tanji_yuka@lilly.com

\begin{abstract}
Bipolar disorder is a recurrent and episodic illness. This survey study assessed experiences and identified clinical insights of individuals with bipolar disorder. An Internet-based monitor system database was screened for patients with bipolar disorder in Japan (February and March 2013). Of 1,050 patients, 457 completed surveys, and results were analyzed with descriptive statistics. Approximately one-fourth of respondents were diagnosed with bipolar disorder on their first visit to medical institutions, although the most common initial diagnosis was depression/ depressive state (65\%). Mean time lag between first-time visit to a medical institution and receipt of correct diagnosis of bipolar disorder was 4 years; one-third of patients experienced more than 5 years of lag time. Three perceived reasons for lapsed time before correct diagnosis were "(patients) Did not consider manic symptoms as illness, and did not tell the doctor about them," "I (patient) did not know of bipolar disorder," and "Lack of communication between my doctor and myself (patient)." Among participants who believed that they were initially incorrectly diagnosed and improperly treated, most experienced socioeconomic problems, such as having long-term inability to work or to study (65\%). Sources of encouragement for participants included "To have someone to consult with" (41\%) followed by having "People around me treat me the same as before" (40\%). Individuals with bipolar disorder reported a time lag of many years before accurate diagnosis, and substantial burden imposed by the illness. Encouragement should be provided for individuals to live positively with bipolar disorder.
\end{abstract}

Keywords: bipolar disorder, mania, depression, perception, diagnosis, cost of illness

\section{Introduction}

Bipolar disorder is a recurrent and episodic illness that exhibits a wide range of mood states. Many patients with the disorder begin to show affective symptoms in early adulthood, with the onset usually occurring in the late teens or early twenties. ${ }^{1}$ Most individuals will have bipolar disorder throughout their lives, resulting in a lifelong burden to the individuals, their families or caregivers, and society. ${ }^{1,2}$ Lish et $\mathrm{al}^{3}$ and Hirschfeld et $\mathrm{al}^{4}$ reported that patients with bipolar disorder experience difficulties caused by the illness in the areas of employment, family, and lifestyle. They also reported that fewer functional problems were seen when the disorder was identified correctly earlier, but that there was a long time lag between the onset of symptoms and the receipt of an accurate diagnosis and treatment. ${ }^{3,4}$ It is commonly thought that the time lag between onset of symptoms and correct diagnosis is due to physicians' lack of understanding of bipolar disorder; however, patients' lack of disease insight could possibly result in an incorrect initial diagnosis because patients may not correctly report their symptoms to physicians. Furthermore, it is unknown which factors may contribute to a change in diagnosis to bipolar disorder after an initial incorrect diagnosis. 
Understanding both circumstances that lead to an initially incorrect diagnosis in patients with bipolar disorder and factors that are involved in assigning the correct diagnosis to those patients may aid in making a proper diagnosis early in the disease process and consequently reduce the burden caused by the lapsed time to the correct bipolar disorder diagnosis. Furthermore, once a patient is correctly diagnosed with bipolar disorder, a multidisciplinary approach that includes social, psychological, and pharmacological treatment should be initiated. It may well be emphasized that most individuals with bipolar disorder may need help or encouragement from others to best control their symptoms and to decrease the burden of illness during their treatment. Masand and Tracy $^{5}$ shed light on patient and caregiver perspectives of the unmet needs in the pharmacological treatment of bipolar disorder; however, a literature search revealed that what type of social and psychological encouragement patients with bipolar disorder need during treatment has not been well surveyed.

Therefore, to elucidate more detailed reasons for lapsed time to correct diagnosis and for correction of diagnosis, as well as to assess which encouragement is needed for individuals with bipolar disorder, we conducted an Internetbased survey, modifying and partially repeating previous studies. ${ }^{3,4}$ Additionally, in comparison with the previous study by Hirschfeld et al, ${ }^{4}$ we aimed to clarify the burden of having bipolar disorder in Japan.

\section{Methods}

\section{Data sampling and inclusion criteria}

This Internet-based survey was conducted in February and March 2013 in Japan. Participants were selected using the following steps (Supplementary materials): first, within a database of individuals who had registered with the Internet website monitor system (Intage Cue Monitor; https://www. cue-monitor.jp/) and who had agreed to participate in health-related surveys upon registration, 1,050 participants who stated that they were diagnosed with bipolar disorder and visited outpatient clinics were identified. Second, these 1,050 participants were contacted via email that included informed consent documents and a screening questionnaire, and 840 participants responded to this email request (response rate: $80 \%$ ). Of those, 561 participants fulfilled the following criteria: 1) had been diagnosed with bipolar disorder by a physician, 2) were currently taking any treatments for bipolar disorder, and 3) fulfilled the criterion of "one-question method" of the Manic Episode Screening Questionnaire $(\mathrm{MES})^{6}$ - one of the screening questions asked participants to mark all answers that applied to them from a list of 15 diseases including bipolar disorder, and those who marked bipolar disorder only and had been receiving any treatments for the disease were included. Third, another email that included the main questionnaire was sent to these 561 participants, and 506 participants responded to this second email (response rate: $90 \%$ ). Out of those 506 participants, 457 participants fulfilled the following criteria: 1) had been diagnosed with bipolar disorder by a physician, 2) were currently taking any treatments for bipolar disorder, and 3) fulfilled the criterion of "diagnostic algorithm method" of MES. All 457 participants were included in the analysis. All participants provided informed consent online after reviewing the complete description of the study. This study complied with the Code of Ethics of the World Medical Association and the Declaration of Helsinki. Institutional review board/ethics committee approval for this study was not sought, because it was not required by the applicable laws and regulations of Japan.

\section{Survey instrument}

This Internet-based survey included 2 self-administered questionnaires: 1) the MES "diagnostic algorithm method," a self-reported questionnaire consisting of 8 yes/no items derived from the 8 diagnostic criteria for bipolar disorder as included in the Diagnostic and Statistical Manual of Mental Disorders-Fourth Edition-Text Revision and is used to screen for bipolar disorders among patients with mood disorder to increase the accuracy of the diagnosis ${ }^{6}$ and 2) a modified version of the questionnaire from the National Depressive and Manic-Depressive Association in the US ${ }^{4}$ (Supplementary materials) which covers 4 major topics: onset and course of illness, path to correct diagnosis, burden of illness, and attitude toward/understanding about the illness. Descriptive statistics were applied in the data analysis, and no statistical test was conducted.

\section{Results}

\section{Demographics and clinical characteristics}

Most respondents were between 30 and 49 years of age (mean age $=40.9$ years, standard deviation $[\mathrm{SD}]=8.9$ years), and $51 \%$ were female. In addition, $44 \%(n=203)$ of participants were at least college graduates, but $29 \%(n=133)$ were unemployed, and $44 \%(n=201)$ had an annual income less than 1,000,000 yen (Table 1). Among those who had married at least once (ie, married, separated/divorced, and widowed; $n=266), 34 \%(n=90)$ had experienced divorce.

\section{Onset and course of illness}

Sixty-four percent $(n=293)$ of participants first exhibited symptoms of bipolar disorder at the age of 20 years or older, 
Table I Demographic characteristics of the sample

\begin{tabular}{|c|c|}
\hline \multirow[t]{2}{*}{ Variable } & \multirow{2}{*}{$\begin{array}{l}\mathbf{N}=\mathbf{4 5 7} \\
\%(n)\end{array}$} \\
\hline & \\
\hline Female & $5 I(23 I)$ \\
\hline \multicolumn{2}{|l|}{ Age (years) } \\
\hline$<29$ & $10(45)$ \\
\hline $30-39$ & $33(153)$ \\
\hline $40-49$ & $4 \mid(188)$ \\
\hline $50-59$ & $13(58)$ \\
\hline $60+$ & $3(13)$ \\
\hline \multicolumn{2}{|l|}{ Marital status } \\
\hline Single, never married & $42(191)$ \\
\hline Separated/divorced ${ }^{a}$ & $13(61)$ \\
\hline Married & $44(203)$ \\
\hline Widowed & $0(2)$ \\
\hline \multicolumn{2}{|l|}{ Educational background } \\
\hline Junior high school or lower & $4(17)$ \\
\hline High school or vocational school & $5 I(235)$ \\
\hline College degree or higher & $44(203)$ \\
\hline Other & $0(2)$ \\
\hline \multicolumn{2}{|l|}{ Employment status } \\
\hline Full-time & $27(124)$ \\
\hline Part-time & $13(59)$ \\
\hline Self-employed & $8(38)$ \\
\hline Housewife & $18(80)$ \\
\hline Student & I (6) \\
\hline Not employed & $29(133)$ \\
\hline Other & $4(17)$ \\
\hline \multicolumn{2}{|l|}{ Household income (yen) } \\
\hline Under $1,000,000$ & $44(201)$ \\
\hline $\mathrm{I}, 000,00 \mathrm{I}-2,000,000$ & $19(87)$ \\
\hline $2,000,00 \mathrm{I}-3,000,000$ & $8(35)$ \\
\hline $3,000,001-4,000,000$ & $7(33)$ \\
\hline $4,000,00 \mathrm{I}-5,000,000$ & $5(22)$ \\
\hline $5,000,001$ or more & $12(57)$ \\
\hline Unknown & $5(22)$ \\
\hline
\end{tabular}

Notes: $\mathrm{N}=$ total number of participants; $\mathrm{n}=$ number of affected participants. ${ }^{a}$ Current status.

but approximately one-third did at a younger age: $18 \%$ $(n=83)$ between ages 15 and 19 years and $18 \%(n=81)$ at an age younger than 15 years. Forty-eight percent $(n=218)$ of participants had visited a medical institution within 1 year of the onset of symptoms, with a mean duration of 3.5 years ( $\mathrm{SD}=5.9$ years) between first onset of symptoms and seeking of medical treatment; however, $13 \%(n=60)$ of participants waited at least 10 years before seeking help. The majority of participants $(\mathrm{n}=266)$ said that they sought help on their own, and one-third $(n=155)$ did so at the suggestion of family, friends, and/or colleagues at work. Approximately half of the participants $(n=251)$ experienced manic symptoms prior to seeking help initially, and an equal number of participants $(\mathrm{n}=251)$ experienced manic symptoms in the lag time between first seeking help and being diagnosed correctly. Eighty-seven participants were members of both groups; that is, they experienced manic symptoms both prior to seeking help initially and in the lag time between first seeking help and being diagnosed correctly. Among those who experienced manic symptoms prior to correct diagnosis $(n=415), 34 \%(n=142)$ did not report their manic symptoms to a physician.

\section{Path to correct diagnosis}

On their first visit to medical institutions, $86 \%(\mathrm{n}=394)$ visited specialists (ie, psychiatrists or psychosomatic physicians). Seventy percent $(n=319)$ of participants presented with depressive symptoms, $15 \%(\mathrm{n}=69)$ were in a mixed state, and $4 \%(\mathrm{n}=17)$ presented with manic symptoms. Approximately one-fourth $(\mathrm{n}=111)$ of participants were diagnosed with bipolar disorder on their first visit to medical institutions, although the most common initial diagnosis was depression/ depressive state $(65 \%, \mathrm{n}=296)$. Other frequently mentioned initial diagnoses were autonomic imbalance $(14 \%, n=66)$, which is commonly used in Japan for psychiatric patients with an undefined diagnosis, and panic disorder $(11 \%, \mathrm{n}=52)$. In addition, $70 \%(\mathrm{n}=322)$ of participants reached the diagnosis of bipolar disorder at the first $(48 \%, \mathrm{n}=221)$ or second $(22 \%, \mathrm{n}=101)$ medical institution they visited. However, the remaining $30 \%(n=135)$ of participants consulted 3 or more medical institutions before receiving an accurate diagnosis. Mean time lag between visiting the medical institution for the first time and the receipt of a correct diagnosis was 4.0 years $(\mathrm{SD}=4.8$ years); approximately one-third $(\mathrm{n}=157)$ of participants received an accurate diagnosis within 1 year, but another third $(\mathrm{n}=162)$ received it after more than 5 years. As shown in Table 2, the 3 major perceived reasons for the lapsed time before correct diagnosis were "Did not consider

Table 2 Reasons for lapsed time to bipolar disorder diagnosis

\begin{tabular}{ll}
\hline Statement & $\mathbf{N}=\mathbf{4 5 7}$ \\
\cline { 2 - 2 }$\%(\mathbf{n})^{\mathbf{a}}$ \\
\hline Did not consider manic symptoms as illness and did not & $39(\mathbf{I 7 6})$ \\
tell the doctor about them & $38(175)$ \\
I did not know of bipolar disorder & $25(I 12)$ \\
Lack of communication between my doctor and myself & $23(107)$ \\
Manic symptoms never appeared & $17(79)$ \\
My doctor did not sufficiently understand bipolar disorder & $15(69)$ \\
My family did not know of bipolar disorder & $12(53)$ \\
My doctor did not take my symptoms seriously & $7(34)$ \\
Lack of support from family and friends & $7(31)$ \\
Did not consider depressive symptoms as illness and & \\
did not tell the doctor about them & $6(28)$ \\
Did not consult a specialist (eg, psychiatry or & \\
psychosomatic medicine) & $3(12)$ \\
Lack of communication among the medical teams & $10(46)$ \\
Other reasons & $8(38)$ \\
Reasons unknown & $6(27)$ \\
Did not take time before diagnosed with bipolar disorder &
\end{tabular}

Notes: $\mathrm{N}=$ total number of participants; $\mathrm{n}=$ number of affected participants. aMultiple answers allowed. 
Table 3 Reasons that served to reach diagnosis as bipolar disorder $(\mathrm{N}=457)$

\begin{tabular}{|c|c|}
\hline \multirow[t]{2}{*}{ Statement } & $\mathbf{N}=\mathbf{4 5 7}$ \\
\hline & $\%(n)^{a}$ \\
\hline $\begin{array}{l}\text { In the course of treatment, my doctor suspected the } \\
\text { possibility of bipolar disorder }\end{array}$ & $57(259)$ \\
\hline Switched to manic state & $30(135)$ \\
\hline When I switched my doctor, my diagnosis changed & $28(128)$ \\
\hline $\begin{array}{l}\text { Asked my doctor about the possibility of being bipolar } \\
\text { disorder, after obtaining some information about the } \\
\text { disease by myself }\end{array}$ & $21(97)$ \\
\hline My family consulted a doctor about my manic symptoms & $10(44)$ \\
\hline $\begin{array}{l}\text { My colleague at work, my acquaintance, or my friend } \\
\text { consulted a doctor about my manic symptoms }\end{array}$ & $2(9)$ \\
\hline Others & $6(27)$ \\
\hline
\end{tabular}

manic symptoms as illness, and did not tell the doctor about them" ( $39 \%, n=176)$, "I did not know of bipolar disorder" $(38 \%, n=175)$, and "Lack of communication between my doctor and myself" (25\%, $\mathrm{n}=112)$.

More than $70 \%(n=328)$ of participants received a diagnosis change before receiving a diagnosis of bipolar disorder. The most frequent number of changes was 1 (33\%, $n=152)$, followed by $2(25 \%, n=112)$. The reason most frequently associated with reaching an accurate diagnosis was "In the course of treatment, my doctor suspected the possibility of bipolar disorder" $(57 \%, \mathrm{n}=259)$, followed by "Switched to manic state" $(30 \%, n=135)$ and "When I switched my doctor, my diagnosis changed" (28\%, $\mathrm{n}=128$ ) (Table 3).

\section{Comparison of participants with and without an early correct diagnosis of bipolar disorder}

Characteristics and behaviors were compared between those survey participants with $(\mathrm{N}=157)$ and those without $(\mathrm{N}=300)$ an early correct diagnosis of bipolar disorder. Early correct diagnosis was defined as a lag time between first-time visit to a medical institution and receipt of correct diagnosis of bipolar disorder of less than 1 year. Demographic baseline characteristics and age at first symptom onset were generally similar between groups; in both groups, more than half of all participants sought medical treatment on their own. A greater percentage of participants with early correct diagnosis experienced manic symptoms before their first visit to a medical institution ( $71 \%$ vs $47 \%)$ and reported to their doctor that they had experienced manic symptoms ( $54 \%$ vs $37 \%$ ) compared to participants without early correct diagnosis. At their first visit to a medical institution, $46 \%$ of participants with early correct diagnosis presented mixed state or manic symptoms compared with $5 \%$ of participants without early correct diagnosis; $43 \%$ of participants with early correct diagnosis presented depressive symptoms compared with $84 \%$ of participants without early correct diagnosis.

\section{Burden of illness}

Among those participants who believed that their correct diagnosis was delayed and who indicated reasons for the delay ( $\mathrm{n}=392$ ), most had experienced socioeconomic problems due to a long-term inability to work at office/home or study at school $(65 \%, n=253)$, interpersonal conflicts with family ( $46 \%, n=181)$, being fired from job or dropping out of school $(46 \%, n=180)$, financial difficulties $(43 \%, n=168)$, and interpersonal conflicts with people other than family $(42 \%, n=166)$. Only $12 \%(n=47)$ reported that their lives were not affected by being incorrectly diagnosed or improperly treated for the illness (Table 4). Eighty percent $(n=367)$ of participants experienced such exacerbation of their manic and/or depressive symptoms that it disturbed their daily lives and functioning, resulting in being hospitalized, taking sick leave, or leaving a job. Of them, $40 \%(n=148)$ were admitted to the hospital.

\section{Attitudes toward and understanding of the illness}

Of all participants, $69 \%(\mathrm{n}=315)$ confessed that they became worried and anxious about their future (eg, work, school, and home). In addition, $53 \%(\mathrm{n}=243)$ of participants felt relieved knowing that they had an illness, but $32 \%(n=145)$ did not believe in their diagnosis. Most $(73 \%, \mathrm{n}=335)$ participants succeeded in accepting the illness as part of their lives, but at the same time, they admitted that they had difficulty

Table 4 Social and economic impact caused by not being able to be diagnosed with bipolar disorder earlier and not receiving appropriate treatment

\begin{tabular}{ll}
\hline Statement & $\mathbf{N}=\mathbf{3 9 2}^{\mathrm{a}}$ \\
\cline { 2 - 2 }$\%(\mathbf{n})^{\mathrm{b}}$ \\
\hline Long-term inability to work at office/home or study at school & $65(253)$ \\
Interpersonal conflicts with family & $46(18 \mathrm{I})$ \\
Fired from job or dropped out of school & $46(180)$ \\
Financial difficulties & $43(168)$ \\
Interpersonal conflicts with people other than family & $42(166)$ \\
Lost the social credit by violence, sexual deviancy, or crime & $12(47)$ \\
Other impact & $8(3 \mathrm{I})$ \\
Had no impact & $12(47)$ \\
\hline
\end{tabular}

Notes: $\mathrm{N}=$ total number of participants; $\mathrm{n}=$ number of affected participants. "Those who answered "Did not take time before diagnosed with bipolar disorder" on Question 7 were excluded from the analysis. bMultiple answers allowed. 
controlling the symptoms of their illness $(72 \%, \mathrm{n}=330)$ and still wondered why they had the illness $(69 \%, n=316)$.

Almost all participants told people that they were close to, such as spouses $(97 \%, n=210 / 216)$, parents $(86 \%$, $\mathrm{n}=359 / 418)$, and siblings $(73 \%, \mathrm{n}=284 / 391)$, that they were diagnosed with bipolar disorder. Fewer participants told their neighbors $(15 \%, n=47 / 312)$, relatives other than parents/siblings $(31 \%, \mathrm{n}=112 / 362)$, and parents-in-law $(49 \%$, $n=95 / 192$ ) about their diagnosis. The 3 major reasons cited by those who did not tell their immediate family (ie, spouse, parents, siblings, and children) about their bipolar diagnosis $(n=162)$ were that they "Didn't think they would understand or sympathize with my illness" $(45 \%, n=73)$, followed by "It is difficult to explain the illness" $(43 \%, n=69)$ and "Telling [them about] the illness will make them worry" $(34 \%, n=55)$. However, many of the participants who told their families about their diagnosis believed that their family understood bipolar disorder (spouse: 75\%, $\mathrm{n}=157 / 210$; parents: $59 \%, \mathrm{n}=213 / 359$; siblings: $60 \%, \mathrm{n}=169 / 284$; children: $59 \%, n=54 / 92$ ). Things that encouraged participants living with bipolar disorder were "To have someone to consult with" $(41 \%, \mathrm{n}=188)$, that "People around me treat me the same as before" ( $40 \%, n=183)$, and that "People around me understand my distress from the illness" (28\%, $\mathrm{n}=128$ ) (Table 5).

From the participants' perspectives, the goal of treatment was "to become able to work outside/at home or study at school at his/her own pace" $(36 \%, n=166)$, followed by "to become able to do things in daily life" $(19 \%, n=89)$ and "to become able to enjoy my hobbies" $(15 \%, n=68)$. To stabilize

Table 5 Encouragement for living positively with bipolar disorder

\begin{tabular}{|c|c|}
\hline \multirow[t]{2}{*}{ Statement } & $\mathbf{N}=\mathbf{4 5 7}$ \\
\hline & $\%(n)^{a}$ \\
\hline To have someone to consult with & $41(188)$ \\
\hline People around me treat me the same as before & $40(183)$ \\
\hline People around me understand my distress from the illness & $28(128)$ \\
\hline People around me leave me alone & $26(117)$ \\
\hline $\begin{array}{l}\text { To have the pharmacological treatment I am taking feel } \\
\text { effective }\end{array}$ & $21(97)$ \\
\hline $\begin{array}{l}\text { My doctor provides advice on not only pharmacological } \\
\text { treatment but also my lifestyle from psychosocial perspective }\end{array}$ & $20(92)$ \\
\hline $\begin{array}{l}\text { My doctor answers any subtle questions I have on my } \\
\text { treatment }\end{array}$ & $18(84)$ \\
\hline My doctor encourages me toward living with bipolar disorder & $8(38)$ \\
\hline $\begin{array}{l}\text { To interact with patients who have same disease - bipolar } \\
\text { disorder }\end{array}$ & $8(37)$ \\
\hline To check the Internet for information on bipolar disorder & $7(32)$ \\
\hline $\begin{array}{l}\text { To read articles about treatment of bipolar disorder in books, } \\
\text { newspapers, or magazines }\end{array}$ & $6(28)$ \\
\hline My doctor explains the specific treatment plan & $6(26)$ \\
\hline
\end{tabular}

Notes: $\mathrm{N}=$ total number of participants; $\mathrm{n}=$ number of affected participants. aultiple (up to 3 ) answers allowed. the mood fluctuation and realize the treatment goal mentioned, participants believed that treatment adherence (36\%, $\mathrm{n}=166)$, trying not to push oneself too much $(25 \%, \mathrm{n}=116)$, and getting sufficient sleep $(12 \%, n=55)$ were the most important factors.

\section{Discussion}

In this survey, we revealed various aspects of patients' experience with bipolar disorder, specifically the reasons for lapsed time to diagnosis and for correction in diagnosis, as well as sources of encouragement for individuals with bipolar disorder. In addition, the results demonstrate that patients with bipolar disorder experience manifold burden due to the illness.

Patients' lack of knowledge about bipolar disorder itself, or even their lack of insight about the manic symptoms of the illness, led to their underreporting of symptoms or miscommunication with physicians, resulting in delayed accurate diagnoses. In a previous study, the authors suggested that misdiagnosis was not only due to physicians' lack of understanding of the disorder but also due to lack of illness symptom disclosure by the patients or the patients' discomfort with disclosure. ${ }^{4}$ Within our study, we explored potential answers for this question by directly asking participants about the reasons for the lapsed time to correct diagnosis. Our results revealed that physicians' careful and comprehensive evaluation of existing symptoms and their awareness of bipolar disorder as an alternative diagnosis could contribute to reaching an accurate diagnosis in a timely manner, even if the patients did not show any evident switch to a manic state. Moreover, the third most commonly mentioned reason for the change of diagnosis ("When I switched my doctor, my diagnosis changed") implies that seeking of a second opinion may be important for a proper diagnosis and therapy if the patient's current treatment is not progressing. For lifelong management of bipolar disorder, our results suggest that patients should be encouraged and supported by their families. We found that patients with bipolar disorder have average, not extraordinary, expectations from their social environment, such as opportunity to consult with others, to be treated as usual, and understanding of their distress.

Results of this study have clinical implications for physicians' daily practice. First, physicians should be aware of the possible diagnosis of bipolar disorder for patients exhibiting a depressive state on their first visit to a medical institution and should provide those patients with information about bipolar disorder. This approach will help patients communicate with their physicians about any manic symptoms they may be experiencing or the possibility of having bipolar disorder. 
Additionally, awareness of a possible diagnosis of bipolar disorder will encourage clinicians to engage targeted screening tools, such as MES, HCL-32, ${ }^{7}$ the Mood Disorder Questionnaire, ${ }^{8}$ and the Bipolar Spectrum Diagnostic Scale. ${ }^{9}$ Second, according to the survey results, physicians should be able to guide patients' family members about how to treat patients in a desirable manner providing appropriate support and encouragement. Finally, clinicians might encourage patients seeking help for depression to be accompanied by a friend or family member who might be able to report on manic or hypomanic episodes more objectively than the patient.

The current survey revealed differences and similarities with a previous report by Hirschfeld et al. ${ }^{4}$ First, the most important difference is the duration between the onset of symptoms and the first visit to medical institutions; compared to patients in the prior study, ${ }^{4}$ a higher proportion of patients in the current study sought help within 1 year of onset of symptoms (36\% vs 48\%, respectively), and a smaller proportion of patients went at least 10 years without seeking help (31\% vs $13 \%$, respectively). However, samples from these 2 surveys were drawn differently, so it cannot be confirmed that recent social enlightenment about bipolar disorder resulted in individuals with symptoms seeking help at medical institutions. Second, our results were similar to those of Hirschfeld et $\mathrm{al}^{4}$ in that less than one-third of patients were diagnosed with bipolar disorder on their first visit to a medical institution, with depression being the most common incorrect initial diagnosis. Thus, lapsed time before reaching a correct diagnosis remains an issue, and further improvement in disease literacy is needed for physicians and patients. Third, we confirmed that patients in Japan are having a similar illness burden as observed in the survey by Hirschfeld et al. ${ }^{4}$ Although patients had higher educational backgrounds compared to the community sample (ie, proportion of participants with a school record of being at least college graduates; $44 \%$ vs $19.9 \%),{ }^{10}$ they also had a higher unemployment rate $(29 \% \text { vs } 4 \%)^{11}$ and a lower income (ie, proportion of participants with an income less than 1,000,000 yen; 44\% vs 9.1\%). ${ }^{12}$ In addition, a nationwide study in Israel has also reported that patients with bipolar disorder have a poor employment outcome compared with the general population, even if they have only been admitted once to the hospital. ${ }^{13}$ Despite several differences between our survey and prior community surveys with regard to population and methods, our results revealed that patients with bipolar disorder carry a similar socioeconomic burden in the US and in Japan.

When comparing participants with and without early correct diagnosis of bipolar disorder, age at symptom onset was comparable between groups. However, more participants with than those without early correct diagnosis experienced manic symptoms before their first visit to a medical institution, and they reported these symptoms to their doctor. Additionally, participants with early correct diagnosis presented a mixed state or manic symptoms rather than depressive symptoms at their first visit to a medical institution. Therefore, improved awareness of manic symptoms and patient education about the importance of reporting of these symptoms to health care providers could improve the rate of early correct diagnosis of bipolar disorder.

The results of our study must be interpreted in light of limitations due to the study design. First, our study is subject to selection bias because participants in Internet surveys are limited to those who have Internet access; therefore, the sample may not represent bipolar patients in general, even though most people in Japan have Internet access $(82.8 \%){ }^{14}$ Likewise, individuals who are registered with the monitor service may not represent the general population. Moreover, participants in this survey might have been subject to an additional selection bias: individuals who are willing to participate in this type of survey may be more likely to complain about the burden of illness, suggesting that real-world clinical settings may be associated with a lesser degree of the problem than what we found in the present study. Second, the data included in this survey were self-reported due to the nature of an Internet-based survey. The diagnosis of participants with bipolar disorders in this study was also self-reported, allowing for the possibility of including participants wrongly diagnosed with bipolar disorder or not being diagnosed at all. To improve the reliability of the diagnosis, we used MES, which is a validated screening questionnaire for identifying bipolar disorders among mood disorder patients of a psychiatric specialty clinic. The one-question method of MES has a satisfactory specificity (0.93), positive predictive value $(0.81)$, negative predictive value $(0.90)$, and a relatively low sensitivity $(0.75)$ in these subjects, suggesting that this test efficiently, but not completely, includes bipolar disorder. ${ }^{6}$ Third, the possibility of recall bias in the survey research limits the ability to make definitive conclusions. Respondents might have difficulty remembering their past events and/or behaviors. Finally, and most importantly, cross-sectional surveys can never address the long-term course of an illness. These limitations may always be associated with Internet surveys, and therefore, have to be acknowledged.

\section{Conclusion}

This report explores the experiences and identifies the clinical insights of individuals with bipolar disorder. Individuals with bipolar disorder reported a lag time of many years between onset of symptoms and accurate diagnosis, and the illness imposes a substantial burden on individuals. 


\section{Acknowledgments}

The authors thank Ms Rieko Nagata, an employee of Eli Lilly, for arranging and conducting this patient survey under supervision of Dr Watanabe. Writing and editorial assistance were provided by Ms Cynthia Bush, Ms Teri Tucker, and Dr Alexandra Heinloth, all from inVentiv Health Clinical, with financial support from Eli Lilly Japan KK.

\section{Disclosure}

This study was funded by Eli Lilly Japan KK. Dr Watanabe has received manuscript fees or speaker's honoraria from Astellas Pharma, MSD, Otsuka Pharmaceutical, GlaxoSmithKline, Shionogi, Daiichi Sankyo, Sumitomo Dainippon Pharma, Mitsubishi Tanabe Pharma, Eli Lilly, Pfizer, Meiji Seika Pharma, and Janssen Pharmaceutical, has received research/grant support from Astellas Pharma, Eisai, MSD, Otsuka Pharmaceutical, Shionogi, Daiichi Sankyo, Sumitomo Dainippon Pharma, Mitsubishi Tanabe Pharma, and Meiji Seika Pharma, and is a consultant of Otsuka Pharmaceutical, Taisho Toyama Pharmaceutical, Sumitomo Dainippon Pharma, Takeda Pharmaceutical, Mitsubishi Tanabe Pharma, and Eli Lilly. Dr Harada contributed to this work as a former full-time employee of Eli Lilly Japan KK. The opinions expressed in this work are solely his and do not represent his current affiliation, the Japanese Ministry of Health, Labour and Welfare. Dr Inoue has received speaker's honoraria from GlaxoSmithKline, Pfizer, Astellas, Eli Lilly, Mitsubishi Tanabe Pharma, Mochida Pharmaceutical, Otsuka Pharmaceutical, Meiji Seika Pharma, Asahi Kasei Pharma, Shionogi, Janssen Pharmaceutical, Takeda Pharmaceutical, and Yoshitomi Pharmaceutical, has received research/grant support from Otsuka Pharmaceutical, Eli Lilly, and Mitsubishi Tanabe Pharma, and is a member of the advisory boards of GlaxoSmithKline, Eli Lilly, Mochida Pharmaceutical, and Tanabe Mitsubishi Pharma. Ms Yuka Tanji is an employee and minor stockholder of Eli Lilly Japan KK. Dr Kikuchi has received manuscript fees or speaker's honoraria from Abbott Laboratories, Astellas Pharma, Eli Lilly, GlaxoSmithKline, Jansen Pharmaceutical, Mochida Pharmaceutical, Otsuka
Pharmaceutical, Pfizer, Mitsubishi Tanabe Pharma, and Yoshitomi Yakuhin within the past 5 years. The authors report no other conflicts of interest in this work.

\section{References}

1. Goodwin FK, Jamison KR. Manic-Depressive Illness: Bipolar Disorder and Recurrent Depression. 2nd ed. Oxford: Oxford University Press; 2007.

2. Miller S, Dell'Osso B, Ketter TA. The prevalence and burden of bipolar depression. J Affect Disord. 2014;169 Suppl 1:S3-S11.

3. Lish JD, Dime-Meenan S, Whybrow PC, Price RA, Hirschfeld RM The National Depressive and Manic-depressive Association (DMDA) survey of bipolar members. J Affect Disord. 1994;31(4):281-294.

4. Hirschfeld RM, Lewis L, Vornik LA. Perceptions and impact of bipolar disorder: how far have we really come? Results of the National Depressive and Manic-Depressive Association 2000 survey of individuals with bipolar disorder. J Clin Psychiatry. 2003;64(2):161-174.

5. Masand PS, Tracy N. Results from an online survey of patient and caregiver perspectives on unmet needs in the treatment of bipolar disorder. Prim Care Companion CNS Disord. 2014;16(4).

6. Kameyama R, Inoue T, Uchida M, et al. Development and validation of a screening questionnaire for present or past (hypo) manic episodes based on DSM-IV-TR criteria. $J$ Affect Disord. 2013;150(2):546-550.

7. Angst J, Adolfsson R, Benazzi F, et al. The HCL-32: towards a selfassessment tool for hypomanic symptoms in outpatients. J Affect Disord. 2005;88(2):217-233.

8. Hirschfeld RM. The Mood Disorder Questionnaire: a simple, patientrated screening instrument for bipolar disorder. Prim Care Companion $J$ Clin Psychiatry. 2002;4(1):9-11.

9. Nassir Ghaemi S, Miller CJ, Berv DA, Klugman J, Rosenquist KJ, Pies RW. Sensitivity and specificity of a new bipolar spectrum diagnostic scale. J Affect Disord. 2005;84(2-3):273-277.

10. Statistics Japan. 平成22年国勢調査からわかったこと [Results of national population census in 2010]. 2010. Available from: http://www. stat.go.jp/data/kokusei/2010/users-g/wakatta.htm. Accessed April 23, 2015. Japanese.

11. Statistics Japan. 労働力調查（基本集計）平成27年(2015年)2月分 [Labor force survey in Feb. 2015]. 2015. Available from: http:// www.stat.go.jp/data/roudou/sokuhou/tsuki/. Accessed April 23, 2015. Japanese.

12. National Tax Agency. 平成25年分 民間給与実態統計調査 [National income survey in 2013]. 2013. Available from: http://www. nta.go.jp/kohyo/tokei/kokuzeicho/minkan2013/pdf/001.pdf. Accessed January 20, 2015. Japanese.

13. Davidson M, Kapara O, Goldberg S, Yoffe R, Noy S, Weiser M. A nationwide study on the percentage of schizophrenia and bipolar disorder patients who earn minimum wage or above. Schizophr Bull. 2016;42(2) 443-477.

14. Ministry of Internal Affairs and Communications. Information and communications statistics database. 平成25年度 通信利用動向 調査の結果 [Survey results of data communication in 2013]. 2014 Available from: http://www.soumu.go.jp/johotsusintokei/statistics/ data/140627_1.pdf. Accessed April 23, 2015. Japanese.
Neuropsychiatric Disease and Treatment

\section{Publish your work in this journal}

Neuropsychiatric Disease and Treatment is an international, peerreviewed journal of clinical therapeutics and pharmacology focusing on concise rapid reporting of clinical or pre-clinical studies on a range of neuropsychiatric and neurological disorders. This journal is indexed on PubMed Central, the 'PsycINFO' database and CAS,

\section{Dovepress}

and is the official journal of The International Neuropsychiatric Association (INA). The manuscript management system is completely online and includes a very quick and fair peer-review system, which is all easy to use. Visit http://www.dovepress.com/testimonials.php to read real quotes from published authors. 